\title{
A narrative inquiry of nursing experiences during the Covid-19 pandemic
}

\author{
Susan Ann Vitale*1, Maureen Lowers-Roach ${ }^{2}$, Lisa A. Lumley ${ }^{3}$ \\ ${ }^{1}$ Barbara H. Hagan School of Nursing and Health Sciences, Molloy College, Rockville Centre, NY, USA \\ ${ }^{2}$ New York Presbyterian Medical Center, New York, NY, USA \\ ${ }^{3}$ South Shore University Hospital, Bayshore, NY, USA
}

Received: February 25, 2021

DOI: $10.5430 /$ jnep.v11n8p1
Accepted: March 24, $2021 \quad$ Online Published: March 28, 2021

URL: https://doi.org/10.5430/jnep.v11n8p1

\begin{abstract}
This research focused on nursing care during the early phase of the Covid-19 pandemic. The experiences of 18 nurses and 3 nurse practitioners were analyzed through qualitative narrative inquiry. Riessman's analytic approach guided identification of thematic similarities. The nurses in this study were emotionally exhausted by the rapid rise in patients and the daily death toll. The challenge of so many gravely ill cases required creative adaptations to address overcrowding and lack of resources. Teamwork proved immeasurable. Nurses advocated for their patients and families and were proud to have worked in this emergency. Nurses dealt with stressors by maintaining prior coping practices and developing new ones and relied on support from their family, hospital and community. A common objective was to establish and maintain the highest-possible levels of care in spite of challenging conditions. Proficiencies developed in coping with unprecedented challenges can help plan for future healthcare crises.
\end{abstract}

Key Words: Covid-19 pandemic, Nursing experiences, Narrative inquiry

\section{INTRODUCTION}

This research was concerned with professional nursing care of patients with coronavirus 2 (SARS-CoV-2) or Covid-19 during its early phase (March to August 2020). The experiences of 18 registered nurses (RNs) and 3 nurse practitioners (NPs) at several locations across the United States (US) were analyzed through qualitative narrative inquiry. Their common objective was to establish and maintain the highestpossible levels of care during this pandemic. Proficiencies developed in coping with unprecedented challenges can help plan for future healthcare crises.

\section{BACKGROUND AND LITERATURE REVIEW}

In early 2020, the Covid-19 pandemic confronted health care providers with a calamity unequaled in scope, severity, and immediacy. This new virus quickly became identified as highly contagious and life-threatening. ${ }^{[1]}$ Although care was provided as quickly and efficiently as possible, the avalanche of new cases and resultant death toll soon taxed the capacity of the health-care system.

At the time of this study initiation, some research on nursing experiences in caring for Covid-19 patients was just beginning to be published. Examples described as follows, are studies of ICU nursing care during that first pandemic year of 2020. A phenomenological study of 14 nurses in $\operatorname{Iran}^{\text {[2] }}$ identified experiences of exhaustion and fear of the virus, yet an improved nursing image. A qualitative study of 34 nurses in China ${ }^{[3]}$ found the need to strengthen nurses' emergency training and knowledge of infectious diseases. Zhang

\footnotetext{
*Correspondence: Susan Ann Vitale; Email: svitale@molloy.edu; Address: Barbara H. Hagan School of Nursing and Health Sciences, Molloy College, Rockville Centre, NY, USA.
} 
et al. ${ }^{[4]}$ found that nurses in Wuhan, China went through a psychological process of ambivalence, emotional exhaustion and then energy renewal. Nyashanu et al. ${ }^{[5]}$ pointed to a need for future pandemic preparedness in England. Sun et al. ${ }^{[6]}$ described various coping styles nurses used including altruism, team support, exercise, meditation, mindfulness, and relaxation techniques. Increased burnout and a fear of becoming infected with Covid-19 was found through a survey of 47 nurses in Saudi Arabia. ${ }^{[7]}$ Coffre and de los Angeles ${ }^{[8]}$ conducted a survey of 127 nurses and reported on how they prioritized a sense of duty while working against fear of contagion and strenuous conditions. Institutional support and coping strategies were also important to them. A systematic review by Fernandez et al. ${ }^{[9]}$ analyzed a collection of 348 nurses from 13 studies. The synthesized findings acknowledged the physical and emotional impact on nurses in providing quality care through supportive nursing teams.

Minimal research was available in that first pandemic year to offer information on the experience of nurses caring for patients with Covid-19. Those early studies pointed to emotional and physical burdens and various ways of contending with that stress. This research attempted to chronicle the first-hand nursing experience in the US during this crisis.

\section{Methods}

The aim of this study was to investigate shared experiences of nurses in the early phase of the Covid-19 pandemic when a lack of prior experience and preparation was available. Tactics to reinforce personal durability and strategies for successful collaborative support when nurses either volunteered or were required to serve were assessed. This research is intended to contribute to the understanding of that nursing care.

This qualitative study was guided by narrative inquiry. Documentation of story in a common experience provided a forum for construction of meaning. Recorded narratives of RNs and NPs served to develop shared themes from the spectrum of circumstance. Participants used storytelling to share their personal and group experiences. "Telling stories about difficult times in our lives creates order and contains emotions, allowing a search for meaning and enabling connections with others" (p.10). ${ }^{[10]}$

The 21 study volunteers represented a diverse purposive sample from several geographic areas. Table 1 displays the demographic variations. A college Institutional Review Board (IRB) approved a study advertisement. Participants signed the IRB approved written consent. All had worked during the early phase of the pandemic. They were interviewed by telephone or Zoom from November to December 2020, for an approximately one-hour recorded conversation with optional follow-up telephone or email contact. The opening research question was: What is the experience of caring for patients diagnosed with Covid-19 during the early pandemic phase? Table 2 presents additional broadly phrased, open-ended, probing questions used to encourage reflection. The principal investigator conducted the interviews with coinvestigators present in many sessions. Interview transcripts were identified by numbers and pseudonyms. Story analysis was conducted sequentially as concurrent data collection progressed. Impressions and conjecture gradually developed into emerging insights. Intensive full analysis followed once data collection was complete.

Table 1. Demographics

\begin{tabular}{ll}
\hline Participants & $\mathbf{N}=\mathbf{2 1}$ \\
\hline Gender & 4 males, 17 females \\
Age Range & 25-64 years old \\
Self-described Ethnicity & 1 Asian, 1 Hispanic, 4 Black/African American (2 from Ghana), 13 White/Caucasian, 2 Jamaican \\
Marital & 4 Married, 7 Single \\
Living in Home & 2 Live Alone; 19 had other adults living with them (parents, siblings, adult children) 8 had younger \\
children at home (infancy-preteen)
\end{tabular}


Table 2. Interview questions

1. What is the experience of caring for patients diagnosed with Covid-19 during the early pandemic phase?
2. Recall the first phase (spring through summer 2020) when you found yourself caring for patients with Covid-19. Please tell us
your own story of what it was like to care for those patients.
3. Please share your reactions and personal responses.
How did you react?
How did it affect you?
How did you cope?
4. How was your life outside of work affected?
5. What recommendations might you have for those working in a similar pandemic or serious health care crisis in the future?

Thematic analysis employed Reissman's ${ }^{[11]}$ narrative strategies. Participant transcripts were compared to the audio tapes and first analyzed individually as an intact story. The intent was to uncover "what" was said in a single interview at a time as they were sequentially obtained. The entire group of interviews were further analyzed together for common thematic elements across all participant stories. Underlying concepts with associated excerpts were coded. Particular cases were identified that illustrated assumptions and thematic similarities. The analysis was repeatedly reviewed by the investigators. Prevalent similarities and themes emerged across the participants, within their experiences, tensions, and resolutions. The narratives were condensed into shorter versions, eliminating non-narrative, dysfluencies, and casual conversation. Themes were created with associated participant quotes. An overarching theme or core construct became evident among all the participant stories. A final mega-story was constructed, connecting the stories, as a way of describing what the interview narratives signify by editing and reshaping what was told, and creating one hybrid story. Trustworthiness of data and analysis was refined by repeated review of recordings, transcripts, field notes, and memos. Participants were given the opportunity to review the analysis and provided critique and support. Participant quotes were included in the final report. ${ }^{[10-12]}$

\section{FindingS}

Most participants resided in New York State with some from California, Florida, Massachusetts, and Oregon in the USA (see Table 1). Of the 3 NPs, 2 worked in hospitals and one in a student health clinic. Their specialized hospital work was subject to change during the pandemic. To meet demand, they were floated to an exclusively Covid-19 unit or found that their own unit was converted into one. Although their stories reflect varying experiences, many commonalities and themes were established (see Table 3). The most significant finding was the realization that Covid-19 had abruptly transformed their perspectives on the momentousness of the healthcare that they were providing. The mounting num-

Published by Sciedu Press ber of cases terminated by death had an inescapable impact on their frames of mind. The unrelenting pressure to continue functioning during this emergent situation took a toll. Anxiety, frustration, and despair were not easily or quickly assimilated.

Table 3. Themes

Overarching Theme - Doing Whatever It Takes
- Relentless Death-Yet the Persistence of Hope
- The Best Possible Care in the Worst Possible Times
- Teamwork/All in This Together
- Patient Advocacy and Family Surrogacy
- Underlying Apprehension of Contracting Covid-19 and Spreading
to Family
- Support and Coping at Home and on the Front Lines
- Proud to be a Nurse
- Skeptics and Mask Opposition

Highlights from several participant stories (Featured Story Examples) reflected the range of nursing roles. These include a New York City, NY ICU nurse (Margarette), an NP at a Los Angeles, CA student health center (Tina), and a nursing instructor and obstetrics nurse on Long Island, NY (Brooke). Themes reflecting commonalties were identified from 21 stories told. An overarching theme emerged from their experiences as "Doing Whatever it Takes." Contextual differences are also represented from their work environments. A mega story concludes the description of findings. Note: The participants used a shortened term of "Covid" instead of Covid-19 in their conversations. The participants' names have been made-up to protect confidentiality.

\section{STORY EXAMPLES}

\subsection{Margarette}

Margarette lives in Westchester, NY with her husband and works in a New York City, NY hospital ICU. At the height of the pandemic, she worked non-stop in an operating room converted to an ICU. She said, "It was challenging, we didn't always have ICU equipment. The room was a tight fit for dialysis, extension cords, and ventilators running. It's so noisy you're lucky if you can hear a pump alarm... my ears 
hurt all shift, the patients needed so much... and you never knew what equipment you'd have or who you'd be working with or giving report to... would it be a nurse from peds, cardiac cath, a nurse who had not been at the bedside for 20 years... or doctors fresh out of school unfamiliar with the equipment. I remember never leaving that small room with 3 ICU patients all on a vent. I literally gowned up and lived in that room for 10-12 hours." She recalled "I'm sweating from the work and I don't know what's on me, fluid is everywhere. It was overwhelming, I was trying so hard to give the care I normally would... people were dying right before you and they're barely wrapped up before the next person is coming into you. It went on like that for months".

\subsection{Tina}

Tina is a Family NP at a Los Angeles, CA university student health clinic with an accumulated rise in positive Covid-19 cases. She said, "I think these students are so young, they don't really get it. We had to isolate a whole fraternity but they didn't seem to understand... some students get angry or yell at us." She tries to pick up on their stress, graduation worries and lack of job prospects telling them, "I want you to do one nice thing for yourself every day... whether it's calling a friend or sitting outside. I ask them who they are in communication with? And did you tell your family you love them this week?" She tries to help them with anxiety and depression related to Covid-19. Teamwork is also important to her. She said, "I think we'll all get through this, but we've got to take care of each other... we're all in this together.' If one of the clinic nurses is having a difficult day she looks to see what she can do and said, "just asking that can help.' To personally cope she said, "I do 15 minutes of relaxation and yoga every morning... and either a beach walk or hike, but I have to go out very early before there's a lot of people without masks."

\subsection{Brooke}

Brooke is a nursing college professor and works in obstetrics at a Long Island, NY community hospital. She indicated that she tries to model a philosophy for her students grounded in how she interacts with patients and selflessly responds to Covid-19 without hesitation. She said, "nurses just step up and answer the call... we rise to challenges." She'll never forget the day she accompanied a Deacon who was heading over to bless the refrigeration trucks parked on the hospital grounds as makeshift morgues and said "I stood there thinking of the families and the people that were in those trucks... funerals were backed up... I'll remember that moment forever. The hospital nurses were extremely busy but “it didn't matter how tired you were. If a nurse or someone was in need you just went. I think that is what nursing is all about. We took care of each other, we lifted each other up when someone was looking like they can't do this anymore. It was us nursing each other." Nurses were doing extra shifts and staying late, yet not complaining. She said, "we tried really hard to keep spirits up." But some nights on the way home she'd have to pull over because she was crying. She recalled looking in the mirror "in the thick of it" and thinking she looked so exhausted and said, "I don't know how I did it. . I believe in God and feel there were many days when he carried me."

\section{THEMES}

Overarching Theme - Doing Whatever it Takes: As the pandemic quickly worsened, the nurses couldn't possibly foresee the developing crisis. They focused instead on doing their best for patients, looking after each other, and trying to keep themselves and their families safe. Confusion and death tolls became alarming within their communities. They needed to support each other and creatively face challenges with strength, hope and a resolve to provide the best possible care during unprecedented circumstances. Doing whatever it takes was a core concept that was evident as guiding the nurses' work during the early months of the Covid-19 pandemic. Following are themes identified across their stories which highlight how the nurses creatively functioned during stressful times.

Relentless Death - Yet the Persistence of Hope: Patients rapidly declined. Refrigerator trucks were temporary morgues and funerals were on hold. One said: "It was very depressing... we walked past the refrigerator trucks to enter work." She thought "oh my God I can't believe how many people are in there." A sense of futility developed as caregivers realized their powerlessness in the face of the Covid19 tsunami. Some relived their memories and wished they could have done more. They lamented how quickly death occurs in that "You turn around and someone is gone." Another said "All ages die, people in their 20s, 30s, 40s... most frightening was there were so many sick at one time and no family there... and they're covering them with a sheet and moving on to the next person." They ran low on "body bags." Sometimes the dead had to be left for hours behind the curtain next to a roommate still cognizant. One sadly recalled that "we had a gentleman from the ED and when they went to put him in bed he was already dead, it was so numbing." Another described how the public blamed susceptibility on conditions such as hypertension or diabetes or rationalized 'it's because they have other issues... but there were so many that didn't have anything in their history... and some very young people." She recalled, "one that was my age... I watched him get intubated, which is hard be- 
cause you put yourself in their position and see how sick he was and had nothing in his history." One said "It wasn't just the elderly... I had a patient who didn't survive and had five kids... how do you deal with that?" She added "It was sad that their family couldn't be there, but it was almost a blessing because some of these people look terrible. They didn't resemble the human that they were after being on all those pressors [vasopressors] and medications and going through special dialysis." One said she'll never forget "a woman had started the Quin drug [chloroquine] and reacted with a dysrhythmia... we tried all types of drugs to save her ...her temperature was going through the roof... nothing worked... it was like, what purpose am I serving here right now because no matter what we did it just wasn't working.'

They held onto hope that their patients would survive. As one said, "miracles did occur... patients got better and went home." Another said, "when the song, I've got a feeling, was played over the hospital intercom it meant someone was extubated or got to go home. . . I got goosebumps, it was so moving." Others said, "my prayers were answered" and that "family got to have their mother come home so it was worth it." One ICU nurse recalled some "success stories of people who were discharged after 90 days." Although the NICU NP worried, he knew the delivery room and NICU were well prepared. While Covid-19 death and sadness enveloped their obstetrics units both he and the nurse participant working in obstetrics felt fortunate that healthy babies were born and tested negative.

The Best Possible Care in the Worst Possible Times: Uncertainty prevailed from a lack of guidelines, reliable information and frequently changing protocols for care of Covid -19 patients. Unprecedented procedures and tasks had to be performed without prior training. They began to experience anxious reactions of increasing powerlessness. One said "everyone was really on edge because we didn't know what to expect." Another said "It started very quickly... we had to cope with 3 or 4 units fully Covid. I was off for 2 days and returned to the whole hospital engulfed in it." Others said "I felt a lot of dread; there's no way to describe this; I was emotionally unprepared; so much to learn on our own; and I didn't know when it would ever end."

They tried to creatively address challenges. Resources and PPEs were not always available. One explained "We were frustrated... you're used to providing a standard of care that now you're not, but you're doing the best you can... this is not normal nursing." Another described cutting renal replacement therapy time in half "to help two people clear some of that build up in their blood instead of just one, but normally we wouldn't do that, we didn't want to do that, but we did it." Another said, "In the beginning there weren't enough vents for everyone... we were trying to take someone else off for someone who needs it more... rationing." She added that "at least now we are adapting other options like bi-pap and high flow and more vents arrived." Temporary ICUs were created and referred to as "pop-ups." Whole floors, even conference rooms, were converted but had structural problems complicating satisfactory functioning with some too small for all the equipment. Others described multiple IV drips akin to a "Christmas tree" stationed by long extension tubes outside patient rooms for "helpers" to monitor. PPEs were not always available.

The nurses said, "We were reusing N-95s and gowns; I was passing my booties (shoe covers) on to the next nurse; we watched YouTube videos on how to clean and reuse our N95s." One nurse asked herself "What was safe... everything [PPEs] for that early time was reused... not disposable... and taking care of five to six COVID patients with no monitors was probably the scariest because we had to keep the doors closed. And when you're not in a typical ICU, the unit doors are solid wood, so you cannot see the patient behind that door... you had to go in, only as little as possible to limit exposure." Another added that eventually "temporary windows were cut into the wooden doors."

Teamwork/All in This Together: Teamwork became an invaluable refuge. As one nurse indicated, "You quickly learn how important it is to support co-workers. . . they're like family... you need to make sure everyone's OK." There was a shortage of trained staff. Many had to work out of their accustomed specialty and comfort zone. A hospital supervisor referred to it as "all-hands-on-deck. .. everyone chipped in." One nurse said the typical "territorial feeling of units was broken down as we all worked together." They had to meet immediate crises by floating as temporary expedients or volunteering to do extra shifts and work on new teams. Another said she "got to meet and work with staff from other departments and service lines... we gained respect for each other." They shared knowledge and taught each other new skills. A poignant expression was "It was on-the-spot training each other." ICU nurses quickly trained nurses from other floors to be "helpers." One nurse without prior ICU experience said, "We didn't have that full ICU skill set, but we could do a lot to help." The ICU nurses were relieved of many basic tasks by helpers, such as repositioning patients and postmortum care. One nurse described it as, "We started a prone team and a body wrapping team." Working as a close team was fittingly described by one nurse as, "We were battling on the front lines together."

Patient Advocacy and Family Surrogacy: As family visits 
had to be severely restricted, nurses provided comfort and support to those still aware. Families could not typically gather at the deathbed and lost a sense of closure. Without family presence, one nurse lamented that "Often we were the only person the patient saw." Nurses frequently had to combine medications, meal delivery, and treatments to cut down on exposure. This limited the alert patient's ability to connect and receive solace. The patients' perspective was described as, "They just see your mask and goggles and can't hear you well; we are faceless; I felt very bad for separated patients and families." One nurse described family calling several times a day yet not having sufficient time to talk with them and added that "families didn't know what was happening and it was scary for them... some were yelling on the phone." Hospital iPads, when available, were often the last means of conversation and visual family contact. One nurse said: "We were also using our personal cell phones to let families contact us and see their relative... I felt like it was the right thing to do." The nurses tried to deal with these issues and said, "I stayed with my patients, so they didn't die alone, even if it increased my risk; I tried to console families by phone; it was hard enough on us but impossible for families to understand.' One nurse added that occasionally "patient services would bring up some family members [wearing PPEs] just to stand outside the room and peek in... it might be their last.” Visitation rules were sometimes stretched for families to grieve or welcome a newborn.

Underlying Apprehension-Contracting Covid-19 and Spreading to Family: All of the participants indicated that they never really felt safe from Covid-19 at work. A nurse who recovered from it in early March said she now understood patients "feeling afraid" because "you don't know what the outcome will be... and now she could connect with patients." In the very beginning, they did not wear masks in hallways. Some were told not to wear a mask in all patient rooms as "it would scare undiagnosed patients." That changed quickly. All the participants could itemize their infection control procedures at work. They soon developed after shift decontamination rituals upon re-entering home. One said, "We figured everything out on our own. We had no guidance." Many separated themselves at home to protect their families. As one nurse had young children, she said "I kept my work shoes and stethoscope in the car." Another said, "We changed out of hospital scrubs into going home clothes... I'd strip before going in the house... he [her husband] sprayed my bag and shoes and I'd put my clothes in a plastic bag and go straight to the shower." Another said "My kids know they don't get hugs and kisses until mommy takes a shower." Some changed in the breakroom or at their car. The hospital parking garage was described as "car doors and trunks open... people changing and stripping down... everything went in a different bag in the trunk and you had wipes." Some of the participants described how they slept on the couch or in a different room to maintain a distance from a spouce or their children.

After an ICU nurse's 95-year-old mother passed in March, her children said "I don't want you to die" as she headed out to work in Boston. Their immune-compromised father worried the family too. So, he stayed at a vacation home to be safe. She explained that "even though that was stressful... he could fend for himself and our children were less stressed." Some nurses told of co-workers who left work because they had elderly parents or young children at home. Another said, "I wasn't that afraid because I knew I'd be well-cared for." One young nurse worked with Covid-19 patients throughout her pregnancy, feeling her unborn baby was "in a safe place." She did test positive for antibodies but had healthy baby.

Some of the nurses developed Covid-19 themselves or had family develop it. A 20-year-old RN, developed Covid-19 in early March with a cough and fever. At that time, staff were only wearing masks in rooms of identified Covid-19 patients. Care for infected relatives at home presented new challenges. Another said "I cared for my Dad at home as soon as he could be discharged. I thought I was going to lose both my parents and they really thought they were going to die." Another recalled that "one of my co-workers lived with her elderly grandma and she did wind up getting it and passing away." A float nurse indicated she probably contracted Covid-19 in January when she was sick with a fever and later had positive antibodies. One participant indicated that he had two young children at home that became covid-19 positive. He described how the children fortunately recovered.

Support and Coping at Home and on the Front Lines: Anxiety compounded by chronic stress persisted. Staff members were seen to cry or become hardened to their fatigue. They kept working even though conditions were often grueling with heavy workloads and no time for a break. One said when she first started floating to Covid-19 floors it was nerve racking. She got a headache and tight chest, but off she went to an unfamiliar floor. She added, "The stress is going to kill you before Covid does, co-workers are getting sick and some dying, quite a few that I knew, yes, and for God's sake... a pastor too." Another thought that "Every day was like running a marathon... it was just non-stop." Many said it was akin to "going into battle." One nurse felt that "not having resources was morally distressing." She spoke of the practice of rationing care and was upset when she found herself thinking "we can't spend all our resources on this one guy, we have other patients." 
Previous methods of coping that worked in the past were supplemented by new options. Lifestyle adaptations included expanding communication on social media with family and friends, exercise, gardening, family time, getting adequate rest, and counseling. One nurse, living in a more rural area indicated she was fortunate to regularly connect with neighbors at a social distance over her backyard fence. Reliance upon prayer and religious practices were described by many as priceless. One said she used "daily devotions to have an open mind, peace, and to protect me while I am protecting myself." They prayed for other frontline workers and patients. Another said, "I feel that all you can do is live your day as full as you can and do your best... I try to turn off stress and take it one day at a time." Two nurses lowered stress by avoiding television news. Another said she was nicknamed "the singing nurse" and shared songs by request as a way to help herself and her patients. A new perspective was "I used to complain about silly things but now I look for something better and move on." Some described the need to "decompress and relax" right after work and even take an unpaid week off "for a mental break." One in a leadership role, looked after his staff to make sure they were managing their challenges. More recently he sees signs of nursing burnout.

Creation of a restful, protected home was important as a means to decompress and reconnect with family. One nurse and mother of a baby tried to "just turn the stress off and have our home be a safe bubble." A nurse's family was positioned to provide singular and irreplaceable emotional support. Personal recollections included that "I talked on the phone every day with my mom and I went for a daily walk with her." Families strained by worry for their "own nurse and loved one" took care of meal preparation, laundry, and childcare.

Tangible demonstrations of hospital support came in the form of free meals, free parking, and laundered scrubs. The nurses described how that support relieved some of their stress, reassured of clean uniform availability and food at work. A greatly appreciated benefit was described as "I could avoid contamination on mass transit and park at the hospital for free... that allowed me to change at the car." The arrival of travel and military nurses reduced patient load and stress, because "they jumped right in and helped." Daily announcements of updated information were appreciated in assurance of evolving progress. Another explained how his hospital used a dog as pet therapy to help the nurses cope with constant pressure.

Community support of food donations, gift cards to coffee shops and public recognition of their efforts were also valued. These demonstrations were fondly remembered now. They said, "I was amazed how people looked out for us; they

Published by Sciedu Press were making sure we had a meal; the cheering and clapping outside the hospital was a morale booster; it was great to be appreciated and recognized; but I'm just doing my job."

Proud to be a Nurse: Nurses understood their contributions during this calamity and were aware that their roles were significant. They were proud of what they were doing. One said, "I signed-up to give my all." Other expressions of this covenant included that "I gave of myself willingly... I kept wanting to go back [doing extra shifts] and help; I did feel like I pushed myself to the challenge ahead; I made a difference; and it solidified my decision to be a nurse." Another didn't consider herself a hero, she said, "we just step up and answer the call... this is what we want to do, we are the backbone in the pandemic. I love being a nurse." Another said "We save lives. I'm very proud of what we do here, even before the pandemic, so I don't think we are heroes." They felt the public may now begin to realize how significant nursing is. Even though such public acknowledgment was inspiring, one added that she "signed up to be a nurse and take care of people but not to put myself at risk."

Skeptics and Mask Opposition: Those in a nurse's community who would not wear a mask and not acknowledge that Covid-19 was dangerous were seen as posing life-threatening risks. These nurses felt disappointed and soon became exasperated. Some hoped to inform doubters and nonbelievers during opportunistic moments. However, others found that such an approach could precipitate an offended and indignant response. An expression of their frustration was that "If they could only see what's happening inside these hospital walls." One said, "I can't stand these people... I wish they could see a video on a day in the life of a nurse during Covid... I' $m$ in here trying to save life." Another said, "I have a big problem with them because look what we have gone through and this is coming again." Other complaints were that "They are causing the spread and putting us at risk; maybe they don't know anyone who got Covid." An ICU nurse was frustrated that her family found masks to be burdensome. Her counterargument that she wore one for 12 hours at a time proved unpersuasive. An NP summed up a common feeling in saying "Some people don't seem to care and think they're more important than everybody else, its unfathomable... we can't say to each his own."

\section{REHABILITATION NURSiNG}

The nurse and supervisor in rehabilitation defined their responsibility as helping both patients and families through the consequences of Covid-19. They were tasked with meeting the many needs of debilitated patients who were physically weakened, disabled, or cognitively slowed. They tried to wean them from ventilators, help them recover strength, and 
adapt to assistive technology. As recovery was unavoidably slow, many could not be discharged to their homes. Their next phase was then a transfer to a long-term care facility.

\section{MEgA STORY}

The nurses in this study were emotionally exhausted by the rapid rise in patients admitted with Covid-19 and the daily death toll. They had no prior experience or preparation for a pandemic. The challenge of so many gravely ill cases required creative adaptations to address overcrowding and lack of resources. It was teamwork that proved immeasurable. They partnered with other staff to do their best under unusual conditions and advocated for their patients and families. In the final analysis, they were proud to have been a nurse in this emergency. As their own families had to be protected from exposure, they developed decontamination protocols upon entering their homes. Some, however, became positive or had family members become infected.

They dealt with all their stressors by maintaining prior coping practices and developing new ones. They relied on support from their family, hospital and community. An upsetting development was the public who refused to wear masks and declared their disbelief in the virus.

Those working in rehabilitation centers had to contend with the sequelae of the virus and its overwhelming effects on patients and their families. They sadly saw the disabling consequences that might respond to their intensive rehabilitation efforts or after a therapeutic trial initiate transfer out to a long-term nursing facility.

Obstetrics and NICU settings offered hope of the future as babies were born and tested negative for the virus. The NP working in the student health center had to preserve her own stamina as she tried to help young adults who were often in disbelief about the virus, naive, angry, feeling stigmatized, or hopeless about future job prospects.

\section{Discussion}

This study investigated challenges during the early phase of the Covid-19 pandemic. Parallels in patient care experiences and concern for safety and coping were found in the participant stories. One of their priorities was the recommendation for nursing to be included in preparation discussions for future pandemics or crises. They also recommended that support from management during such stressful times include increased staff meetings and communication, spiritual and wellness initiatives, and training on ICU procedures.

Recently published qualitative research offers cross-cultural support for the findings in this study. A cross-sectional study of 557 nurses in Madrid ${ }^{[13]}$ identified a lack of training, fear of becoming infected and spreading Covid-19 to family, heavy workloads, moral suffering, and emotional exhaustion. Murat, Kose, and Savaser ${ }^{[14]}$ identified stress and burnout among front-line nurses in Turkey. An online survey of 231 nurses in Israel, ${ }^{[15]}$ found a strong dedication to the job they were doing along with emotional burdens, concerns of personal risk of contracting Covid-19, and insufficient protection at work. In Denmark, a qualitative study ${ }^{[16]}$ of 57 nurses identified uncertainty, increased burden and yet a feeling of pride. The need for ongoing managerial attention, support, and a visible presence was also noted. In Iran, Sadati et al. ${ }^{[17]}$ (2021) interviewed 24 hospital nurses during the March 2020 outbreak. They found a lack of preparedness, concern of exposure risk to themselves and their families, anxiety, along with a feeling that they were making a sacrificial commitment. Not reported in our study was their finding of social stigma related to family and community in seeing the nurses as potentially contagious.

One phenomenological study of 2021 with 28 hospital nurses ${ }^{[18]}$ was conducted in the US. The nurses had intense emotions and feelings of being scared, isolated, angry, betrayed, overwhelmed, exhausted, helpless, grief stricken, and at a loss. Also identified were self-care measures and a hope for the best, feeling they are not invincible and lucky not to have Covid-19. These findings are similar in many ways to our study.

A study ${ }^{[19]}$ of Jordanian nurses emphasized the responsibility management has to implement stress reduction strategies for nurses, arrange support services, ensure their safety, conduct briefings and be accessible to staff. Such measures are applicable to the findings in our study. The American Organization for Nursing Leadership ${ }^{[20]}$ recommends that institutions focus on employee well-being and the provision of supportive services as was similarly expressed by participants in our study. Jean Watson's Theory of Human Caring and the Caritas ${ }^{[21]}$ describe the need for nurses to be able to take good care of themselves as well as their patients. Such priorities need to be encouraged by workplaces as was highlighted throughout this study.

Limitations in this study are acknowledged. It compiled impressions of a select group of participants which may not be found in other groups. Their endurance and resilience through the crisis was evident. Others who left the profession, lost a family member, or developed Covid-19 long-term sequelae would undoubtedly have provided a different narrative. 


\section{Conclusion}

Nursing as a profession has and continues to work to identify Covid-19 positivity, heal the infected, comfort the dying, console families, and manage the rehabilitation and long-term consequences of this disease. The nurses in this study had to educate themselves on new procedures while trying to keep themselves and their families safe. Their ingenuity and team spirit guided them despite times when there was a lack of adequate supplies, resources, and staff. They maintained a high standard of care in the face of moral dilemmas and physical stress. Some of them and their families were infected with Covid-19. They creatively managed their self-care through positive self-talk, prayer, song, exercise, and connection with co-workers. These courageous and resilient nurses and nurse practitioners worked together to deliver the best care possible during unusual times. It is important that we strive to improve healthcare during the remainder of this pandemic as well as in future crises. This can be accomplished by involving the nursing profession in planning and in the encouragement of research to prepare for their unique role as caregivers, healers and lifesavers in times of national disaster. The need for nurse leaders to be involved in policy at all levels of government to ensure they can influence health policy is recommended for dealing with future pandemics. ${ }^{[22]}$

\section{CONFlicts OF InTEREST Disclosure}

The authors declare that there is no conflict of interest.

\section{REFERENCES}

[1] Johns Hopkins University and Medicine. Coronavirus Resource Center. 2020. Available from: http://www. coronavirus.jhu.edu/ map.html

[2] Bahramnezhad, Fatemeh, Asqari, et al. Dancing with death in the dust of coronavirus: The lived experience of Iranian nurses. Creative Nursing. 2020; 26(4): 82-89. PMid:32917841 https: //doi.org/10.1891/CRNR-D-20-00046

[3] Tan R, Yu T, Luo K, et al. Experiences of clinical first-line nurses treating patients with Covid-19: A qualitative study. Journal of Nursing Management. 2020; 28(6): 1381-1390.

[4] Zhang Y, Wei L, Li H, et al. The psychological change process of frontline nurses caring for patients with Covid-19 during its outbreak. Issues in Mental Health Nursing. 2020; 41(6): 525530. PMid:32497451 https://doi.org/10.1080/01612840. 2 020.1752865

[5] Nyashanu M, Pfende F, Ekpenyong M. Exploring the Challenges faced by frontline workers in health and social care amid the Covid-19 pandemic: Experiences of frontline workers in the English midlands region, UK. Journal of Interprofessional Care. 2020; 34(5): 655661. PMid:32674701 https://doi.org/10.1080/13561820.2 020.1792425

[6] Sun N, Wei L, Shi S, et al. A qualitative study on the psychological experience of caregivers of COVID-19 patients. American Journal of Infection Control. 2020; 48(6): 592-598. PMid:32334904 https://doi.org/10.1016/j.ajic.2020.03.018

[7] Almubark R, Almaleh Y, BinDhim N, et al. Monitoring Burnout in the Intensive Care Unit and Emergency Department during the Covid-19 Pandemic: The Saudi Arabian Experience. Middle East Journal of Nursing. 2020; 14(2): 12-21.

[8] Coffré JAF, de los Ángeles Leví Aguirre P. Feelings, Stress, and Adaptation Strategies of Nurses against COVID-19 in Guayaquil. Investigacion \& Educacion En Enfermeria. 2020; 38(3): 1-14.

[9] Fernandez R, Lord H, Halcomb E, et al. Implications for COVID19: A systematic review of nurses' experiences of working in acute care hospital settings during a respiratory pandemic. International Journal of Nursing Studies. 2020. PMid:32919358 https : //doi.org/10.1016/j.ijnurstu.2020.103637
[10] Riessman CK. Narrative Methods for the Human Sciences. Thousand Oaks, CA: Sage; 2008; 1-76, 183-200. https ://doi .org/10.398 7/COM-08-S (N) 29

[11] Reissman CK. Narrative analysis. Newbury Park. CA: Sage; 1993.

[12] Polit DF, Beck CT. Designing and Conducting Qualitative Studies to Generate Evidence for Nursing. In D. F. Polit, C. T. Beck (Eds.), Nursing Research: Generating and Assessing Evidence for Nursing Practice. Philadelphia: Wolters Kluver/Lippinott Williams \& Wilkens. 2017; 560-569.

[13] GONZÁLEZ-GIL MT, et al. Nurses' perceptions and demands regarding COVID-19 care delivery in critical care units and hospital emergency services. Intensive \& Critical Care Nursing. 2021.

[14] Murat M, Köse S, Savaşer S. Determination of stress, depression and burnout levels of front-line nurses during the COVID-19 pandemic. International Journal of Mental Nursing. 2021; 30(2): 533 543. PMid:33222350 https ://doi.org/10.1111/inm.12818

[15] Sperling D. Ethical dilemmas, perceived risk, and motivation among nurses during the COVID-19 pandemic. Nursing Ethics. 2021; 28(1): 9-22. PMid:33000673 https : //doi .org/10.1177/0969733020 956376

[16] Marsaa K, Mendahl J, Heilman H, et al. Pride and Uncertainty: A Qualitative Study of Danish Nursing Staff in Temporary COVID19 Wards. Journal of Hospice \& Palliative Nursing. 2021; 23(2): 140-144.

[17] Sadati AK, Zarei L, Shahabi S, et al. Nursing experiences of COVID19 outbreak in Iran: A qualitative study. Nursing Open. 2021; 8(1): 72-79. PMid:32904939 https : //doi .org/10.1002/nop2.604

[18] Iheduru-Anderson K. Reflections on the lived experience of working with limited personal protective equipment during the COVID19 crisis. Nursing Inquiry. 201; 28(1): e12382. PMid:33010197 https://doi.org/10.1111/nin.12382

[19] Shahrour G, Dardas LA. Acute stress disorder, coping self-efficacy and subsequent psychological distress among nurses amid COVID19. Journal of Nursing Management (John Wiley \& Sons, Inc.). 2020; 28(7): 1686-1695. PMid:32767827 https ://doi.org/10.1111/ jonm. 13124

[20] Joslin D, Joslin H. Nursing leadership Covid-19 insight survey: Key concerns, primary challenges, and expectations for the future. American Organization for Nursing Leadership. 2020. 
[21] Watson J. Human Caring Science: A Theory of Nursing. Sudbury, MA: Jones \& Bartlett Learning. 2012.

[22] Stribling J, Clifton A, McGill G, et al. Examining the UK Covid-
19 mortality paradox: Pandemic preparedness, healthcare expenditure, and the nursing workforce. Journal of Advanced Nursing (John Wiley \& Sons, Inc.). 2020; 76(12): 3218-3227. PMid:32914471 https://doi.org/10.1111/jan. 14562 